\title{
Evaluasi Kualitas Pelayanan Angkutan Pemukiman Yang Melayani Di Kawasan Perumahan Citraindah City, Kabupaten Bogor
}

\section{Evaluation of The Quality of Residential Transportation Services That Serve in The Housing Area of Citraindah City, Bogor Regency}

\author{
Amanda Ristriana Pattisinai ${ }^{1}$ \\ Agata Janice Pusparani Armilennia Br.Siagian² \\ ${ }^{1}$ Program studi D3/D4 Transportasi , Universitas Negeri Surabaya, Kampus Ketintang, Unesa, Surabaya 60231. Email : \\ ristriamanda@gmail.com \\ ${ }^{2}$ Program studi D3/D4 Transportasi , Universitas Negeri Surabaya, Kampus Ketintang, Unesa, Surabaya 60231.
}

\begin{abstract}
Abstrak
Angkutan pemukiman adalah pelayanan angkutan tidak dalam trayek yang melayani dari kawasan pemukiman ke beberapa titik tujuan pusat kegiatan.Pusat kegiatan yang dimaksud adalah pusat perkantoran, pusat perdagangan, dan kawasan industri. Salah satu perumahan yang mempunyai angkutan pemukiman adalah perumahan Citraindah City, kabupaten bogor yang diberi nama angkutan kawasan. Tujuan dari penelitian ini adalah, untuk menganalisis apakah angkutan pemukiman di perumahan Citraindah City sudah memenuhi standar TOD, memahami apakah kinerja operasional pelayanan angkutan dari angkutan pemukiman ini sudah dilaksanakan dengan baik dan memuaskan para pengguna serta memberikan rekomendasi kepada pihak perumahan agar mempertahankan pelayanan yang sudah dilaksanakan dengan baik dan meningkatkan pelayanan yang masih belum dilaksanakan dengan baik. Metode yang digunakan dalam penelitian ini, adalah metode observasi lapangan, kepustakaan, wawancara, dokumentasi, kinerja operasional angkutan umum dan standar TOD. survei dilakukan secara online dengan jumlah responden 70 dengan 48 orang perempuan dan 22 orang laki-laki. Setelah dilakukannya analisis, berdasarkan standar TOD dari 5 indikator penilaian, angkutan kawasan masih belum memenuhi 3 indikator penilaian dan analisis berdasarkan kinerja operasional angkutan umum dengan metode kuesioner online bahwa kecepatan perjalanan, jumlah kendaraan yang beroperasi, frekuensi pelayanan, waktu tempuh perjalanan, waktu tunggu harus diperbaiki pelayananannya sedangkan kecepatan perjalanan, keamanan dan kebersihan halte, lokasi, kondisi halte, sikap petugas, dan pelayanan petugas, tariflongkos, dan waktu pelayanan.
\end{abstract}

Kata Kunci: Angkutan pemukiman; kinerja operasional angkutan; pelayanan; standar TOD

\begin{abstract}
Residential transportation is the transportation services that do not serve on the route from the residential area to the several destination points of the activity center. The Office center, trading center, and industrial area are the several of the activity centers. One of the housings that have residential transportation is Citraindah City, Bogor district, their residential transportation name is angkutan kawasan. The purpose of this research is to analyze if the residential transportation already fulfilled the TOD standard, to comprehend if the operational performance of transportation services well done and to satisfied the passengers, and also to recommend Citraindah City developer to maintain their good services and increase the services has not been implemented properly. The method used in this research is the method of field observation, literature study, interview, documentation, operational performance of transportation services, and the TOD Standard. The survey was done online with the resulting number of respondents is 70 people with 48 women and 22 men. after analysis based on TOD Standard with 5 assessment indicators, the residential transportation still not fulfilled 3 assessments indicators, and the result of analysis based on the operational performance of transportation services with interview online, number of operating vehicles, frequency of service, travel time and waiting time must be improved the services, meanwhile travel speed, safety and cleanliness of the shuttle stop, the location, the condition of the shuttle stop, the attitude of the officer, rates of fee, and the service time has already good.
\end{abstract}

Keywords: Operational performance of transportation services; residential transportation; service; TOD Standard 


\section{PENDAHULUAN}

Semakin meningkatnya pertumbuhan penduduk, maka makin banyak developer perumahan yang membangun perumahan dipinggir kota, salah satunya adalah perumahan Citraindah City di Jongogol, Kabupaten Bogor. Berdasarkan data survei MTI tahun 2020, masih banyak masyarakat menggunakan angkutan pribadi membuat pihak perumahan memikirkan untuk membuat fasilitas angkutan perumahan untuk mengurangi penggunaan angkutan pribadi yang diberi nama angkutan kawasan atau dikenal dengan angkutan pemukiman. Angkutan kawasan mempunyai jumlah 4 kendaraan yang beroperasi untuk melayani di seluruh perumahan. Terdapat 3 fasilitas halte untuk menaikan dan menurunkan penumpang angkutan kawasan, yang berada di samping SPBU, depan fresh market (pasar modern), dan taman. Tujuan dari penelitian ini adalah untuk menganalisis angkutan kawasan apakah sudah memenuhi kualifikasi berdasarkan dengan standar TOD, memahami apa saja indikator faktor yang sudah terlaksana dengan baik dan memuaskan pengguna dengan kinerja operasional angkutan umum dan memberikan rekomendasi kepada pihak perumahan agar dapat mempertahankan pelayanannya. Metode yang digunakan pada penelitian ini adalah metode kinerja operasional pelayanan angkutan umum dengan kuesioner online, standar TOD, observasi lapangan, kepustakaan (library study).

\section{METODE}

Metode Berdasarkan hasil survei online untuk data kinerja operasional pelayanan angkutan umum di dapatkan 70 responden, dengan jumlah responden wanita 48 orang dan responden laki-laki 22 orang. Dari hasil survei online tersebut didapatkan data untuk menganalisis kinerja operasional pelayanan angkutan umum dan dilakukannya analisis data menggunakan aplikasi SPSS (Statistikal Package for the Social Sciens) sehingga didapatkan hasil bahwa dari 12 indikator pertanyaan yang diberikan berdasarkan kepentingan atau yang diharapkan oleh penumpang dan kinerja atau yang dirasakan oleh penumpang realibel atau terpercaya dan diperoleh perbedaan yang signifikan terhadap kedua variabel. Berikut adalah diagram alir dalam perencanaan analisis terhadap angkutan pemukiman di perumahan citraindah city.

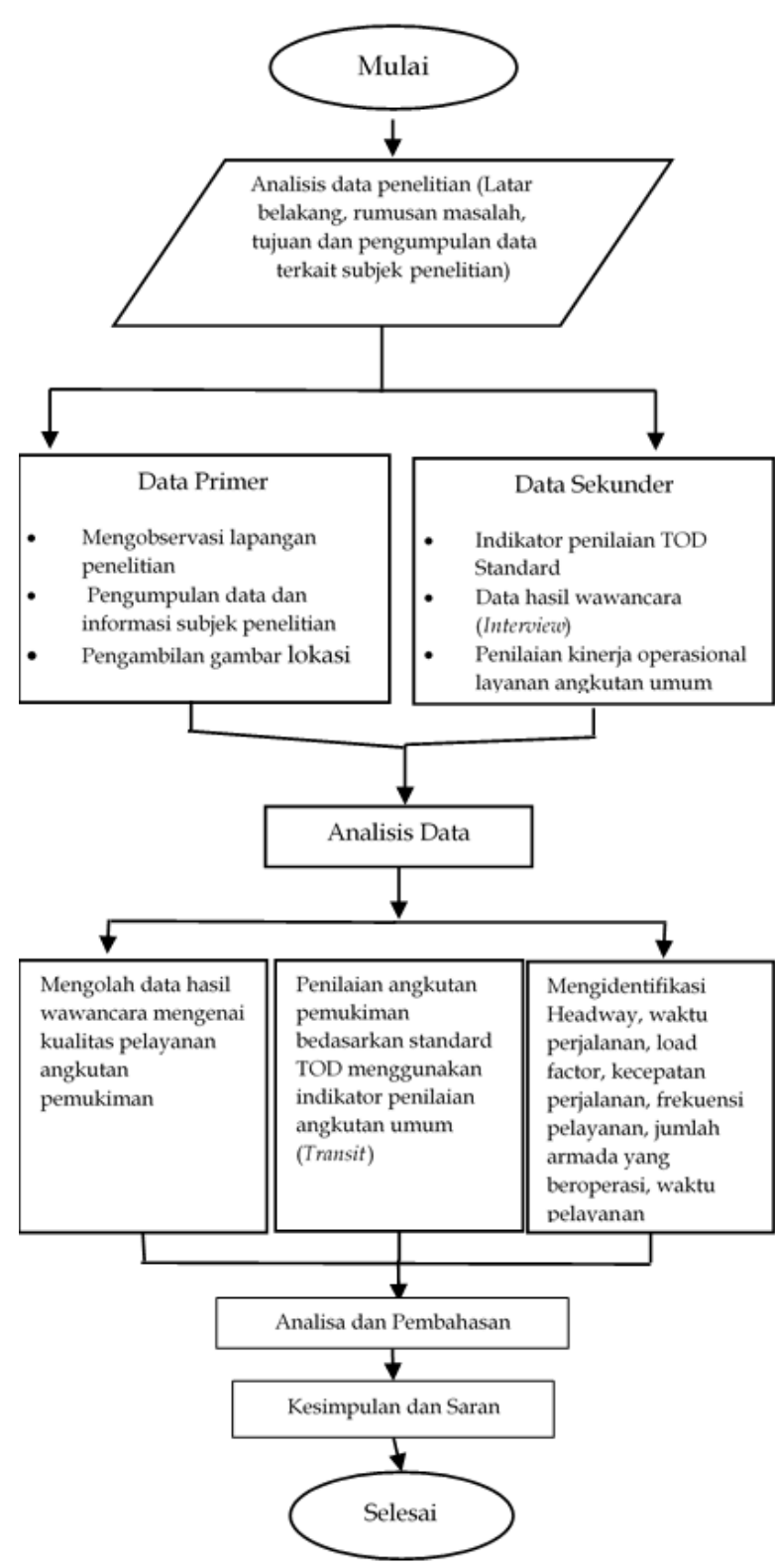

Gambar 1. Diagram Alir Perencanaan Analisis 


\section{HASIL DAN PEMBAHASAN}

A. Gambaran Umum Lokasi Penelitian

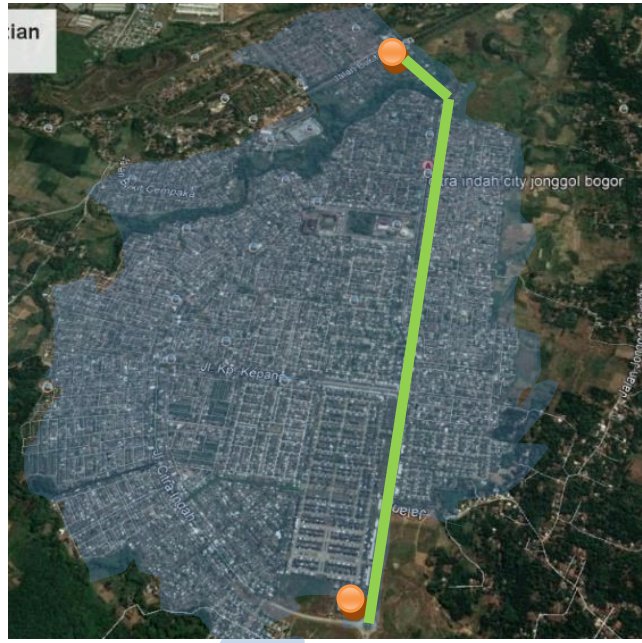

Gambar 2. Denah Lokasi Penelitian

B. Hasil Analisis Dengan Metode Standar TOD

Dari hasil analisis penilaian menurut standar TOD dengan 5 indikator penilaian, angkutan kawasan mendapatkan hasil sebagai berikut :

Tabel 1 Penilaian Angkutan Kawasan Berdasarkan Standar TOD

\begin{tabular}{|c|c|c|c|c|c|}
\hline No & $\begin{array}{c}\text { Aspek } \\
\text { yang } \\
\text { dinilai }\end{array}$ & $\begin{array}{c}\text { Standar } \\
\text { TOD }\end{array}$ & $\begin{array}{c}\text { Penilai } \\
\text { an }\end{array}$ & $\begin{array}{c}\text { Keterang } \\
\text { an }\end{array}$ & Gambar \\
\hline $\begin{array}{l}1 \\
.\end{array}$ & $\begin{array}{l}\text { Frekue } \\
\text { nsi } \\
\text { Pelaya } \\
\text { nan }\end{array}$ & $\begin{array}{l}\text { Minimal } \\
15 \text { menit } \\
\text { antara jam } \\
7 \text { pagi } \\
\text { hingga } \\
\text { jam } 10 \\
\text { malam }\end{array}$ & $\begin{array}{l}\text { Tidak } \\
\text { memen } \\
\text { uhi }\end{array}$ & $\begin{array}{l}\text { Frekuensi } \\
\text { pelayana } \\
\mathrm{n} \quad 15 \\
\text { menit - } \\
30 \text { menit, } \\
\text { dari } \\
\text { pukul } \\
06.30 \\
\text { WIB } \\
\text { hingga } \\
\text { pukul } \\
17.30 \\
\text { WIB }\end{array}$ & \\
\hline $\begin{array}{l}2 \\
.\end{array}$ & $\begin{array}{l}\text { Gedun } \\
\mathrm{g} \\
\text { dalam } \\
\text { wilaya } \\
\mathrm{h} \\
\text { pemba } \\
\text { nguna } \\
\mathrm{n}\end{array}$ & $\begin{array}{l}500 \quad- \\
1000 \quad \mathrm{~m} \\
\text { dari } \\
\text { stasiun } \\
\text { angkutan } \\
\text { dan } \\
\text { layanan } \\
\text { angkutan } \\
\text { berkualifik } \\
\text { asi }\end{array}$ & $\begin{array}{l}\text { Sudah } \\
\text { memen } \\
\text { uhi }\end{array}$ & $\begin{array}{l}\text { Jarak } \\
\text { tempuh } \\
\text { berjalan } \\
\text { yang } \\
\text { dapat } \\
\text { diakses } \\
\text { oleh } \\
\text { semua } \\
\text { orang } \\
\text { sejauh } \\
42,78 \\
\text { meter } \\
(\mathrm{m})\end{array}$ & $m$ \\
\hline
\end{tabular}

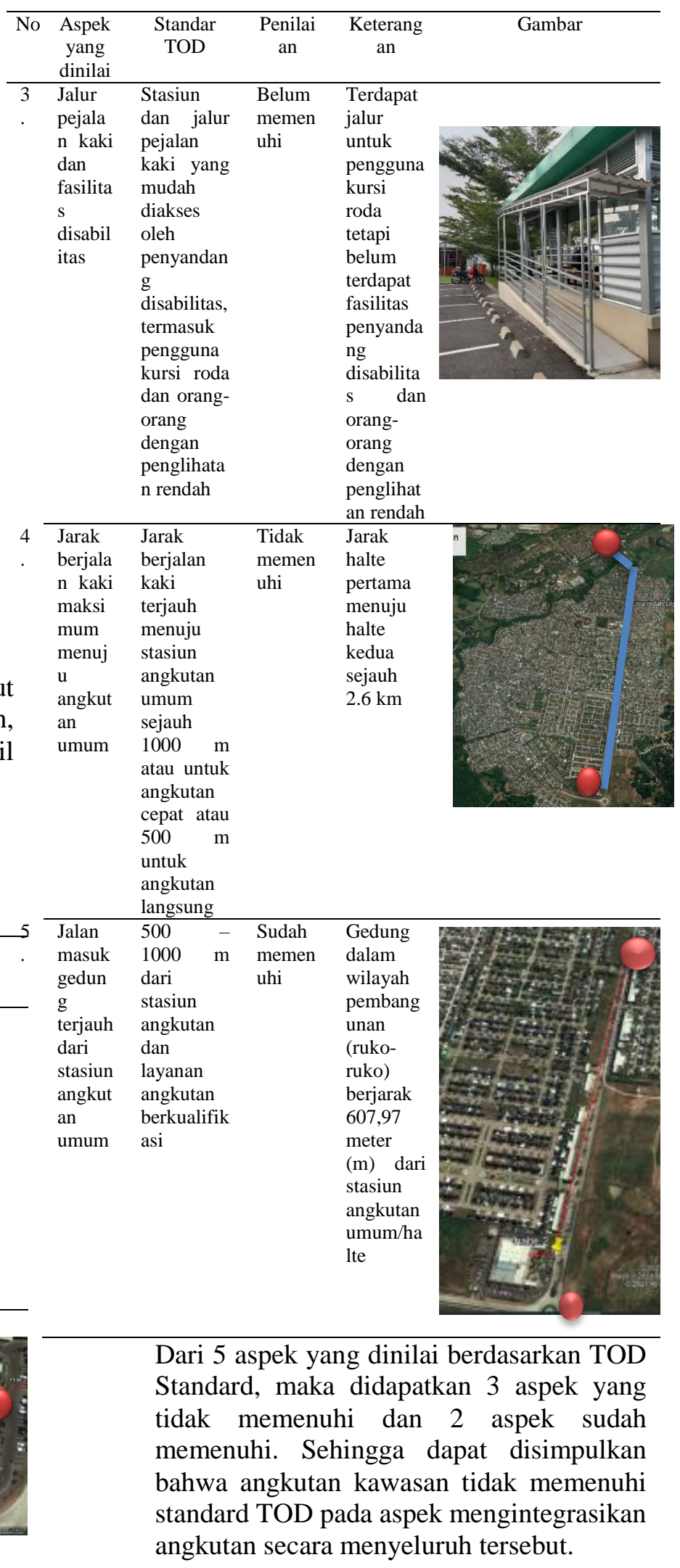

C. Hasil Analisis Dengan Metode Kinerja Operasional Pelayanan Angkutan Umum Pada analisis menggunakan metode kinerja operasional pelayanan angkutan umum dilakukan secara penyebaran kuesioner online dikarenakan adanya hambatan 
pengambilan data di masa pandemi covid19, berdasarkan hasil penilaian analisis dengan pedoman kinerja operasional pelayanan angkutan umum berdasarkan data primer didapatkan hasil jumlah responden sebagai berikut :

1. Jenis Kelamin

Jumlah responden yang didapat pada kuesioner yang dilakukan secara online dengan google form adalah 70 responden. Dengan jumlah responden 22 orang lakilaki dan 48 orang perempuan. Data diatas dapat dilihat dengan grafik yang disajikan dibawah ini :

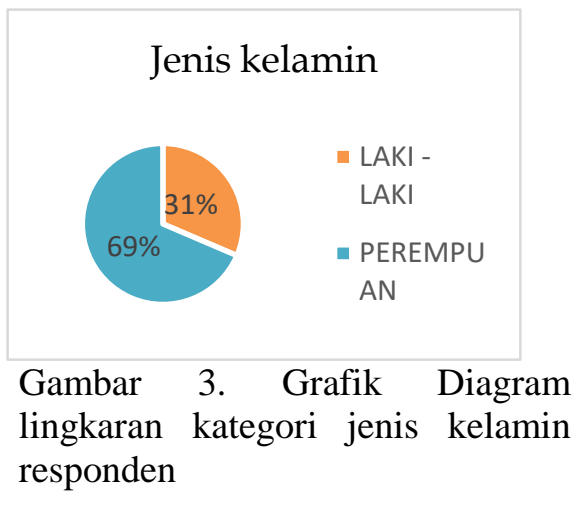

Dari hasil analisis data diatas yang disajikan dalam diagram lingkaran, dapat dilihat bahwa pengguna angkutan kawasan yang paling banyak adalah perempuan dengan persentase $69 \%$ sedangkan laki-laki hanya $31 \%$

\section{Jenis Pekerjaan}

Pada kategori jenis pekerjaan terdapat 5 kategori jenis pekerjaan, dengan hasil analisis data paling banyak yaitu $62 \%$ atau 43 orang. Data tersebut disajikan dalam diagram lingkaran dibawah ini :

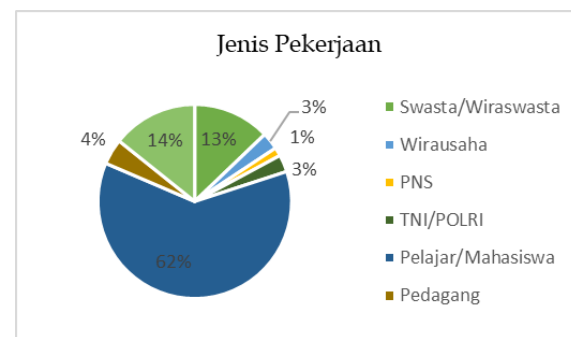

Gambar 4. Grafik diagram lingkaran kategori jenis pekerjaan responden

Dari gambar diagram lingkaran diatas, dapat dilihat bahwa pengguna paling banyak yang menaiki angkutan kawasan adalah pelajar/mahasiswa dengan jumlah total $62 \%$.

3. Usia

Jumlah responden usia pada kuesioner melalui google form ini merupakan kategori yang menentukan kalangan umur rentan berapakah yang lebih efektif menggunakan angkutan kawasan. Berikut adalah gambar diagram lingkaran berdasarkan usia :

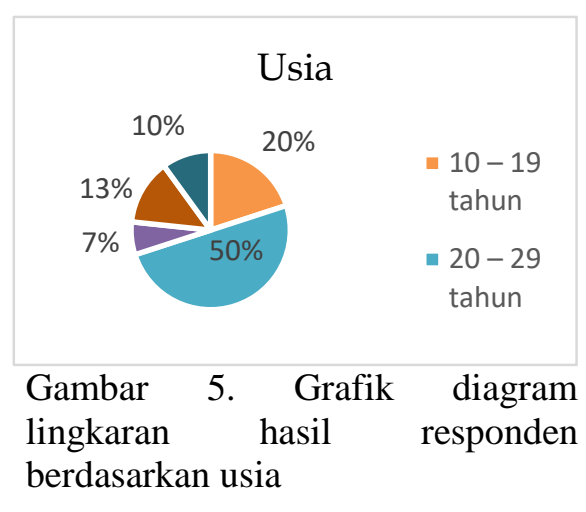

Pada analisis data gambar grafik diagram diatas, dapat dilihat pengguna paling banyak yang menaiki angkutan kawasan adalah usia 20 - 29 tahun dan yang kedua adalah 10 - 19 tahun. Dari range umur diatas dapat ditarik kesimpulan bahwa tujuan kegiatan menaiki angkutan kawasan tersebut adalah untuk pulang dan berangkat ke sekolah serta melakukan perjalanan menuju tempat-tempat umum di dalam perumahan seperti taman, pasar modern, dan setelah 
melakukan perjalanan jauh menggunakan feeder bus dari Jakarta lalu transit menggunakan angkutan kawasan.

4. Pendidikan Terakhir

Jumlah responden berdasarkan pendidikan terakhir merupakan indikator responden dimana dalam tingkatan pendidikan merupakan suatu proses penyesuaian manusia terhadap lingkungan sekitarnya. Terdapat 7 kategori pendidikan terakhir yang disajikan, sehingga dapat membandingkan perbedaan pendapat terhadap angkutan.

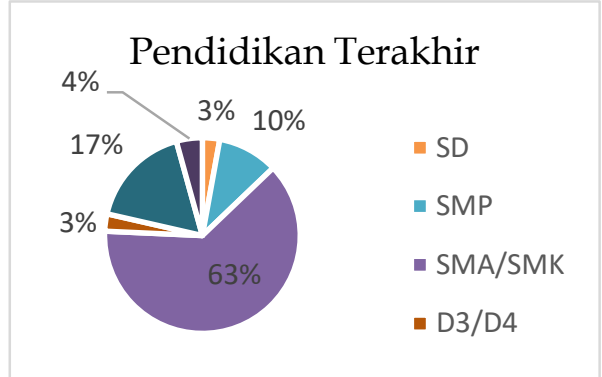

Gambar 6. Grafik diagram lingkaran hasil responden berdasarkan pendidikan terakhir

Dari hasil analisis data diatas yang disajikan dengan diagram lingkaran didapatkan hasil bahwa pengguna paling banyak yang menggunakan angkutan kawasan adalah SMA/SMK.

5. Pendapatan Rata-Rata Perbulan Dalam pengambilan data responden menggunakan indikator pendapatan rata-rata pebulan untuk mengetahui dan merencanakan bagaimana penyesuaian tarif dan mengetahui kalangan mana saja yang menaiki angkutan pemukiman tersebut. Berikut merupakan data analisis yang disajikan dalam diagram lingkaran berdasarkan pendapatan rata-rata perbulan :

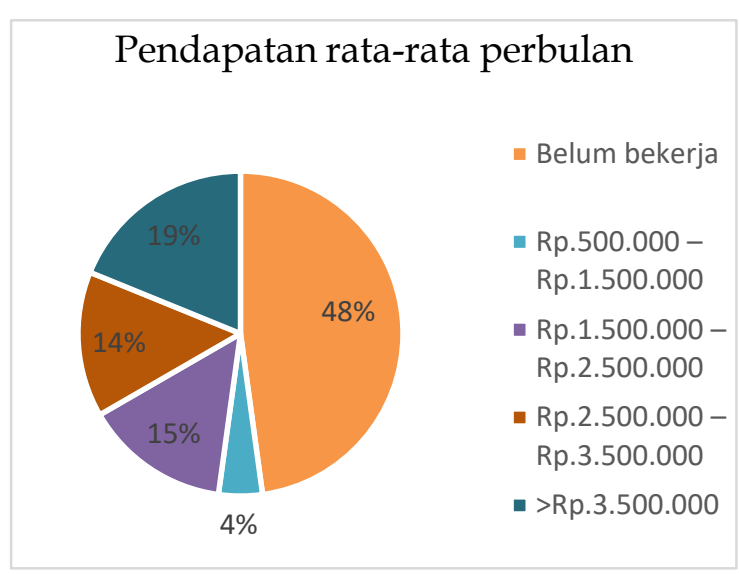

Gambar 7. Grafik diagram lingkaran hasil responden berdasarkan pendapatan rata-rata perbulan

Dari hasil analisis data diatas yang disajikan dalam grafik diagram lingkaran dapat dilihat bahwa pengguna paling banyak yang menaiki angkutan kawasan adalah pengguna yang belum bekerja dengan jumlah $48 \%$ dan yang kedua adalah > Rp.3.500.000, dari hasil diatas dapat ditarik kesimpulan bahwa pengguna angkutan kawasan terintegrasi secara menyeluruh sampai dengan rentang pendapatan > Rp.3.500.000 dan UMR Jabodetabek. Maka dari itu, pengguna angkutan kawasan tidak hanya dari kalangan pendapatan dibawah UMR saja tetapi setara dengan UMR dan diatas nya masih menaiki angkutan kawasan.

Pada analisis dengan menggunakan aplikasi SPSS (Statistikal Package for the Social Sciens) didapatkan hasil bahwa dari ke 12 indikator pertanyaan yang diberikan berdasarkan kepentingan atau yang diharapkan dan kinerja atau yang dirasakan oleh penumpang didapat hasil $\mathrm{t}$ hitung $>\mathrm{t}$ tabel dengan 18,296>1,997 yang merupakan terdapat perbedaan rata-rata hasil responden antara variabel kinerja pelayanan dengan variabel pelayanan yang diharapkan pengguna. Dari analisis 12 indikator pertanyaan dapat dilakukan analisis kuadran terhadap kinerja dan harapan pelayanan angkutan kawasan Citraindah City, Kabupaten bogor dapat di sajikan pada tabel berikut ini : 
Tabel 2. Perhitungan faktor-faktor kepuasan pengguna

\begin{tabular}{|c|c|c|c|c|c|}
\hline \multicolumn{6}{|c|}{ PERHITUNGAN FAKTOR-FAKTOR KEPUASAN PENUMPANG } \\
\hline \multirow[t]{3}{*}{ No } & Pertanyaan & Penilaian & Penilaian & Penilaian & Penilaian \\
\hline & & Kinerja & Kepentin & Kinerja & Kepentingan \\
\hline & & & & $\mathrm{X}: 70$ & $\mathrm{Y}: 70$ \\
\hline \multirow[t]{2}{*}{1} & Waktu & 221 & 261 & 3,16 & 3,73 \\
\hline & $\begin{array}{l}\text { tempuh } \\
\text { perjalanan }\end{array}$ & & & & \\
\hline \multirow[t]{2}{*}{2} & Waktu & 196 & 280 & 2,80 & 4,00 \\
\hline & tunggu & & & & \\
\hline \multirow[t]{2}{*}{3} & Tarif/ongko & 270 & 264 & 3,86 & 3,77 \\
\hline & $\mathrm{s}$ & & & & \\
\hline \multirow[t]{2}{*}{4} & Waktu & 231 & 270 & 3,30 & 3,86 \\
\hline & pelayanan & & & & \\
\hline \multirow[t]{4}{*}{5} & Jumlah & 180 & 288 & 2,57 & 4,11 \\
\hline & kendaraan & & & & \\
\hline & yang & & & & \\
\hline & beroperasi & & & & \\
\hline \multirow[t]{2}{*}{6} & Kecepatan & 236 & 287 & 3,37 & 4,10 \\
\hline & perjalanan & & & & \\
\hline \multirow[t]{4}{*}{7} & Keamanan & 236 & 297 & 3,37 & 4,24 \\
\hline & dan & & & & \\
\hline & kebersihan & & & & \\
\hline & halte & & & & \\
\hline 8 & Lokasi & 233 & 284 & 3,33 & 4,06 \\
\hline \multirow[t]{2}{*}{9} & Kondisi & 235 & 292 & 3,36 & 4,17 \\
\hline & Halte & & & & \\
\hline \multirow[t]{2}{*}{10} & Sikap & 243 & 287 & 3,47 & 4,10 \\
\hline & petugas & & & & \\
\hline \multirow[t]{2}{*}{11} & Pelayanan & 254 & 293 & 3,63 & 4,19 \\
\hline & petugas & & & & \\
\hline \multirow[t]{3}{*}{12} & Frekuensi & 206 & 287 & 2,94 & 4,10 \\
\hline & pelayanan & & & & \\
\hline & Rata-rata jun & ah total sel & hnya & 39,16 & 48,43 \\
\hline
\end{tabular}

Dari hasil analisis menggunakan aplikasi SPSS untuk menentukan diagram kartesius berdasarkan kinerja pelayanan dan harapan pengguna angkutan kawasan melalui 12 indikator kuesioner diatas, di dapatkan hasil diagram sebagai berikut :

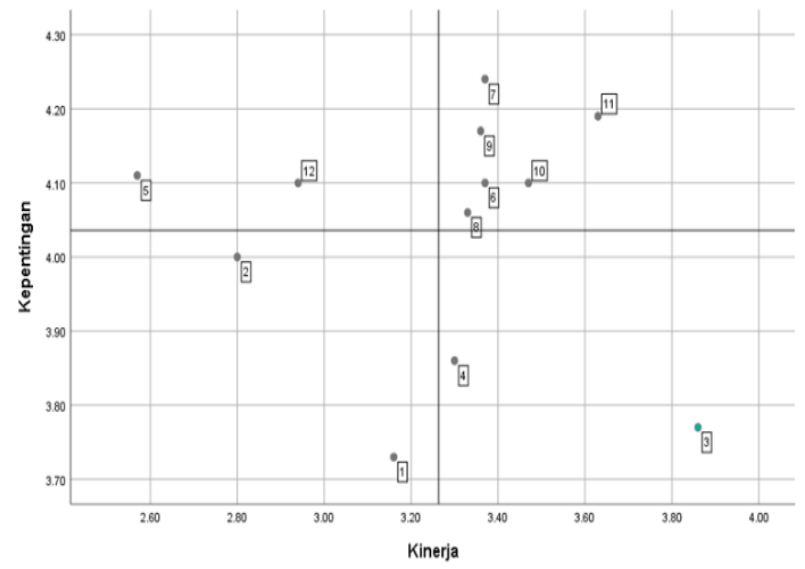

Gambar 8. Diagram kartesius berdasarkan kepentingan dan kinerja pelayanan angkutan kawasan

Dari hasil diagram diatas, dapat disimpulkan sebagai berikut :

a) Kuadran I (Prioritas Utama)
Pada kuadran I terdapat indikator jumlah kendaraan yang beroperasi (5) dan frekuensi pelayanan (12), maka dapat disimpulkan bahwa indikator jumlah kendaraan yang beroperasi dan frekuensi pelayanan harus ditingkatkan karena kinerja pelayanannya yang diberikan rendah.

b) Kuadran II (Pertahankan Prestasi)

Pada kuadran II terdapat indikator kecepatan perjalanan (6), keamanan dan kebersihan halte (7), lokasi (8), kondisi halte (9), sikap petugas (10), dan pelayanan petugas (11), maka dapat disimpulkan bahwa indikator-indikator diatas sudah diberikan secara baik dan optimal.

c) Kuadran III (Prioritas Rendah)

Pada kuadran III, terdapat indikator waktu tempuh perjalanan (1), waktu tunggu (2), maka dari itu dapat disimpulkan bahwa indikator-indikator diatas dikatakan kurang penting dan kinerja pelayanan yang diberikan penyedia jasa kurang baik.

d) Kuadran IV (Berlebihan)

Dalam kuadran IV terdapat indikator tarif/ongkos (3), dan waktu pelayanan (4), sehingga dapat disimpulkan bahwa 2 indikator diatas merupakan indikator yang dianggap tidak penting tetapi kinerja atau pelayanan yang diberikan penyedia jasa baik atau berlebihan.

D. Rekomendasi Yang Dapat Dilakukan Pihak Perumahan

Berdasarkan hasil analisis penilaian berdasarkan standard TOD dan penilaian kinerja pelayanan operasional angkutan umum menggunakan metode kuesioner didapatkan beberapa rekomendasi sebagai berikut :

Hasil Analisis Penilaian Berdasarkan Standar TOD : Peningkatan kinerja pelayanan berdasarkan frekuensi pelayanan, dimana jadwal beroperasi diubah dari yang semula dari pukul 06.30 WIB 17.30 WIB menjadi 06.30 WIB - 22.00 WIB

Penyediaan fasilitas untuk penyandang disabilitas, termasuk pengguna kursi roda dan orang-orang dengan penglihatan rendah pada stasiun dan jalur pejalan kaki yang mudah diakses.

Pada aspek penilaian jalan masuk gedung terjauh dari stasiun angkutan umum, agar dapat memenuhi standar TOD maka harus diberikan halte di beberapa titik yang masuk kedalam gedung dalam wilayah pembangunan.

Rekomendasi Terhadap Penilaian Kinerja Pelayanan Operasional Angkutan Umum

Rekomendasi yang dapat diberikan oleh pihak perumahan untuk meningkatkan kinerja pelayanan

Proteksi/Desember 2021 Volume 3 No. 2 
angkutan kawasan terdapat pada kuadran I, III dan IV yang termasuk dalam indikator kuadran tersebut adalah jumlah kendaraan yang beroperasi, frekuensi pelayanan, waktu tempuh perjalanan, waktu tunggu, tarif/ongkos dan waktu pelayanan.

\section{SIMPULAN}

Berdasarkan hasil survei responden terhadap analisis kinerja pelayanan operasional angkutan umum dan analisis penilaian berdasarkan Standar TOD dapat disimpulkan sebagai berikut :

1. Berdasarkan hasil analisis penilaian standar TOD diatas, dari 5 aspek yang dinilai didapatkan 3 aspek yang tidak memenuhi dan 2 aspek yang sudah memenuhi. 3 aspek yang belum memenuhi adalah aspek frekuensi pelayanan, jalur pejalan kaki dan fasilitas disabilitas, dan jarak berjalan kaki maksimum menuju angkutan umum dan yang memenuhi standar gedung dalam wilayah pembangunan, dan jalan masuk jalan masuk gedung terjauh dari stasiun angkutan umum.

2. Penilaian kinerja pelayanan operasional angkutan umum melalui kuesioner menggunakan google form, didapatkan data bahwa ke-12 pertanyaan kuesioner yang diberikan valid sesuai dengan Cronchbach's Alpha yang mendapatkan nilai > 0,60, dan untuk $r$ tabel variabel penilaian kinerja dan penilaian terhadap harapan pengguna didapat $>0,235$ ( $\mathrm{r}$ tabel). Melalui diagram kartesius, indikator ke-12 pertanyaan yang diberikan yang harus ditingkatkan adalah kecepatan perjalanan, waktu perjalanan, tarif/ongkos, jumlah kendaraan yang beroperasi, waktu tunggu dan waktu pelayanan.

3. Rekomendasi yang dapat diberikan kepada pihak perumahan berdasarkan standar TOD adalah 3 aspek yang belum memenuhi standar TOD yaitu, frekuensi pelayanan, jalur pejalan kaki dan fasilitas disabilitas dan jarak berjalan kaki maksimum menuju angkutan umum. Sedangkan, untuk kinerja pelayanan operasional angkutan umum yang direkomendasikan untuk peningkatan atau optimalisasi kinerjanya adalah indikatorindikator yang masuk kedalam kuadran I, III dan IV pada diagram kartesius yaitu, kecepatan perjalanan, waktu perjalanan, tarif/ongkos, jumlah kendaraan yang beroperasi, waktu tunggu dan waktu pelayanan.

\section{REFERENSI}

Peraturan Menteri Perhubungan Nomor PM 32 Tahun 2016 tentang Penyelenggaraan Angkutan Orang Dengan Kendaraan Bermotor Umum Tidak Dalam Trayek

Statistik Komuter Jabodetabek (2019), Hasil Survei Komuter Jabodetabek 2019

Henry Eryanto, Darma Rika S. (2014). Evaluasi Program Wajib Belajar Pendidikan Dasar Di DKI Jakarta pada periode 2008 - 2011

Zelafehad Mega Naskay, Agustinus Fritz Wijaya (2020). Evaluasi Kinerja Sistem Informasi Kepegawaian Pada Dinas Kependudukan dan Catatan Sipil Salatiga Menggunakan COBIT 5

Lintang Imania (2018). Pengaruh Experiental Marketing dan Kepercayaan Merek (Brand Trust) Terhadap Kepuasan Pelanggan Melalui Keputusan Pembelian (Studi Kasus Pada Konsumen Larissa Aesthetic Center Cabang Panjaitan, Semarang)

Ira Rahmadani (2018). Kualitas Pelayanan Penempatan Tenaga Kerja Pada Dinas Tenaga Kerja Kota Makassar

Fandy Tjiptono, Ph.D (2014). Pemasaran Jasa Prinsip, Penerapan, Penelitian

Kotler, P. \& Keller, K.L. (2012), Manajemen Pemasaran Jilid I Edisi ke 12. Jakarta: Erlangga

ITDP (2017), Penilaian TOD Standard

Yohanes T. Safe, I Made Udiana, Rosmiyati A. Bella (2015). Evaluasi Kinerja Angkutan Umum Trayek Terminal Oebobo - Terminal Kupang PP dan Terminal Kupang - Terminal Noelbaki PP

Dirjen Perhubungan Darat (2002). Pedoman Teknis Penyelenggaraan Angkutan Penumpang 
Umum di Wilayah Perkotaan Dalam Trayek Tetap dan Teratur

Dirjen Perhubungan Darat (2001), Panduan Pengumpulan Data Angkutan Umum Perkotaan
Undang-Undang Nomor 22 Tahun 2009 tentang Lalu Lintas dan Angkutan Jalan 